\title{
THE EXTRACT SOYBEAN OF LOCAL VARIETIES AS REDUCE ADVANCED GLYCATION END PRODUCTS AND HEMOGLOBIN A1C IN TYPE 2 DIABETES MICE
}

\author{
JULIANA CHRISTYANINGSIH ${ }^{1 *}$, TAUFIQURRAHMAN ${ }^{1}$, SUJONO $^{2}$ \\ ${ }^{1}$ Department of nutrition, Politeknik Kesehatan Kemenkes Surabaya, Surabaya, Indonesia. ${ }^{2}$ Department of Medical Laboratory \\ Technology, Politeknik Kesehatan Kemenkes Yogyakarta, Yogyakarta, Indonesia. Email: juliana_analis@yahoo.co.id
}

Received: 07 April 2018, Revised and Accepted: 18 July 2018

\section{ABSTRACT}

Objectives: Glucose and amino acids or fat in diabetic patients if were oxidized to form a compound amadori product (hemoglobin A1c [HbA1c]) and intermediate dicarbonyl that uses reactive carbonyl groups to bind with the amino acids to form advanced glycation end products (AGEs). Soybean is classified as a low index glycemic and content of polyphenol compounds are reported to have various biological activities, which are beneficial to health. Project objectives: The aim of this study was to determine the effect of extract soybean of local varieties obtained on AGEs and HbA1c.

Methods: This study was a randomized pretest-posttest control group design. The amount of 28 Mus musculus Balb/C was divided into seven groups. The control group was divided four, while the test group was given extracts of three varieties of soybean, that is, Gema, Wilis, and Argomulyo at a dose equivalent to $1 \mathrm{~g}$ of soy $/ \mathrm{kg}$ BW/day for 25 days. Type 2 diabetes (T2D) mice made with the administration of STZ at a dose of $55 \mathrm{mg} / \mathrm{kg}$ in mice.

Results: There is a sign of differences in HbA1c levels in the group of mice, and there are different levels of AGEs, though not statistically significant in the group of mice.

Conclusions: The extract soybean was a positive effect on the levels of AGEs and HbA1c in T2D mice.

Keywords: Glycine max (L.) Merr., Advanced glycation end products, Hemoglobin A1c, Type 2 diabetes mice.

(C) 2018 The Authors. Published by Innovare Academic Sciences Pvt Ltd. This is an open access article under the CC BY license (http://creativecommons. org/licenses/by/4. 0/) DOI: http://dx.doi.org/10.22159/ajpcr.2018.v11i11.26513.

\section{INTRODUCTION}

The data from a global study, in 2011, showed that the number of diabetes mellitus (DM) patients had reached 366 million and is expected to increase to 552 million by 2030. DM prevalence in Indonesia is rising from year to year, and many people are still in productive age. Diabetic complications are the systemic vascular disease (accelerated atherosclerosis), cardiovascular disease, the microvascular disease in the eye as a cause of blindness and retinal degeneration (diabetic retinopathy) [1], cataracts, and renal impairment as a cause of renal failure and diabetic neuropathy [2]. The prevalence of Type 2 diabetes (T2D) patients is quite large, usually due to the relative failure of $\beta$-cells and insulin resistance, especially in people with underweight or obese. Usually, once diabetes is detected, this syndrome has developed and there have been one or two complications. Complications in diabetes seem to correlate with blood glucose concentration so that excessive glucose is suspected to be a major cause of tissue damage [3]. This phenomenon is caused by the condition of hyperglycemia in vivo role in the process of free radical formation [4]. Hyperglycemia causes auto-oxidation of glucose, protein glycation, and activation of polyol metabolism pathways which further accelerate the formation of reactive oxygen compounds $[5,6]$.

Hemoglobin A1c (HbA1c) is formed from a bond of glucose with an amide group on the valine at the end of the beta-globulin chain $\mathrm{Hb}$ of a normal adult. The first stage occurs an aldimine covalent bond in the form of a stable Schiff base and the second stage of amadori rearrangement becomes a stable form of ketamine. In a hyperglycemic state, it will increase Schiff base formation between aldehyde glucose groups with lysine, arginine, and histidine residues. In addition, collagen glycosylation products and other proteins in the blood vessel walls to form irreversible advanced glycation end products (AGEs), which continue to accumulate in the vessel wall [7]. The AGEs have a number of potentially pathogenic chemicals and biological properties allegedly contributed to diabetic complications.
There are three mechanisms of increased oxidative stress in DM through non-enzymatic glycation of proteins, polyol-sorbitol (aldose reductase) pathways, and glucose auto-oxidation and the role of various antioxidant compounds or substances in reducing oxidative stress due to increased glycemic status [8]. The glycation process non-enzymatic, also known as Maillard's reaction, is a series of reactions between carbohydrates and protein-free amino groups. The initial intermediates (Amadori products, 1-amino, 1-deoxy, and 2-ketoses) eventually resulted in the formation of AGEs characterized by detection of pentosidine and N-carboxy-methyl lysine (CML) [9]. Accumulation of AGEs results in changes in the structural properties of tissue and tissue aging [10]. Accumulation of AGEs is believed to contribute to the gradual development of diabetic complications $[11,12]$.

Soybean is a type of plant with polyphenol compounds that are reported to have various biological activities, which are beneficial to health, such as preventing oxidative stress. Food intake of soybean seeds is known to reduce risk factors for chronic diseases. Certain components of soybean, especially isoflavones, saponins, Vitamin C, and tocopherols, are associated with the protective effect of oxidative stress [13].

Christyaningsih proved that soy extract can lower pollutants levels and lipid peroxidation in the blood [14]. Yulia using other varieties of soybean suggests varying biological activity in decreasing lipid peroxidation activity, potentially as an antioxidant [15]. Further, research conducted by Yulia proving of several varieties of soybean seeds that exist, Argomulyo varieties provide the highest antioxidant effect [16]. The high content of isoflavones in soybeans has also proven to be significantly beneficial for postmenopausal women in terms of increasing levels of collagen, elasticity, and skin epithelial thickness [17]. In addition to isoflavones, soybean seeds of Detam-2 variety proved to contain other active antioxidant compounds hexadecanoic acid methyl ester and hexadecanoic acid and ethyl ester. Isoflavones in soybeans are also shown to inhibit bone resorption and stimulate bone formation in menopausal women $[18,19]$. This study aims to analyze the effect 
of soybean extract formulation (Glycine max [L.] Merr.) on AGEs and HbA1c. The use of this experimental animal was declared ethical by the Research Ethics Committee of Health Polytechnics, Surabaya.

\section{MATERIALS AND METHODS}

This study has an experimental design of study and randomized pretest-posttest control group design. The experimental animals used were mice Balb/C, male, 10-week-old, weighing 20-35 g, healthy physically with clear-eyed features, glossy fur, and active motion, obtained from the Biochemistry Laboratory, Airlangga University. The use of this animal has been authorized by the Research Ethics Committee of Politeknik Kesehatan Kemenkes Surabaya. The animals were acclimatized for about 1 week, given high carbohydrate and lipid feed for 2 weeks and drinking water ad libitum.

\section{Materials and instrument}

AGEs kits and HbA1c, STZ, metformin, dextrose 10\%, haematoxylin and eosin staining, starter pellet feed and aqua, kinetic maceration , rotary evaporator, water bath electric (BUCHI Water bath B-480), Mesh 20, blender (grinder), ELISA, analytical balance, centrifuge, mouse cage, NGT feeding tube, micropipette and tip, conical tube, vortex, test tube, syringe $3 \mathrm{ml}$, glucometer and laboratory glassware.

\section{Preparation of sample}

T2D animal models: 28 male mice were fasting for $\pm 4 \mathrm{~h}$ and then the mice measured blood glucose levels and body weight. The next $2 \mathrm{~h}$ (after the tail injury dries), the mice were injected with streptozotocin solution at $55 \mathrm{mg} / \mathrm{kg}$ BW intraperitoneally, then the mice were fed and drank 10\% dextrose solution ad libitum then left in the cage for 2 days. On the $3^{\text {rd }}$ day, after the mice were fasting $\pm 4 \mathrm{~h}$, measured blood glucose levels. The results of blood glucose measurements showed that the mice had been conditioned to T2D [20]. The mice were randomly assigned to seven treatment groups with four replications, i.e. four control groups and three groups of soybean extract treatment. During the treatment, the mice were fed and drank on ad libitum, and on day $12^{\text {th }}$, measurements of blood glucose, HbA1c, and AGE levels were measured.

\section{Extraction}

Soybeans were obtained from the Research Institute of various beans and tubers, Malang, East Java, with varieties of Wilis, Gema, and Argomulyo. The soybean seeds obtained from Balitkabi, Malang, are certified and harvested at the same plant age. The soybean seeds are ground with a blender, and the powder that has been obtained is then sieved with a mesh size of 20 to form a finer and more uniform powder. Soybean seed powder that has been sieved then weighed to determine the weight. Eliminated fat content with hexane (pa), then in maceration ethanol (pa) using kinetic maceration tool [21]. The extraction results were concentrated using a rotary evaporator. The concentration was continued with water bath electric until the extract was obtained.
Soy extract dissolved in Na- CMC with equal doses of $1 \mathrm{~g}$ of soybeans (Anjasmoro/ Detam II/ Argomulyo)/kg BW/oral/day/mice, given in the morning with NGT feeding tube [22]. At the end of the study, the mice were sacrificed by cervical dislocation; their blood was drawn and surgically removed for liver and pancreatic tissue.

\section{The analysis of AGEs, Oxiselect ${ }^{\mathrm{TM}}$ AGE competitive ELISA kit, cat. no STA-817}

This test uses the technique of immunoassay enzyme competitive inhibition (ELISA). A monoclonal antibody specific to AGEs labeled on a microplate. Competitive inhibition reactions between biotin labeled AGEs and those not labeled AGEs (found on standards or samples) with antibodies coated specifically for AGEs. After incubation, the unbound conjugate will be separated during washing. Next, add the conjugated Avidin-horseradish peroxidase (HRP) to each well on the microplate and then incubate. The number of conjugated HRP bonds is inversely proportional to the concentration of AGEs in the sample. After addition of the substrate solution, the measured color intensity is inversely proportional to the concentration of AGEs in the sample, which is read in the ELISA Reader tool.

\section{The analysis of HbA1c kit Sigma-Aldrich cat. code: BCR405RM}

$\mathrm{Hb}$ glycosylate or HbA1c can be measured by several methods such as affinity chromatography, electrophoresis, immunoassay, or boronate affinity method. Specimens used for the measurement of HbA1c: Capillary or venous blood with anticoagulants (EDTA, citrate, or heparin).

The location of the research at Biochemistry Laboratory of Airlangga University and the analysis examination was held at Research Institute of Media Husada Surabaya Corp., Laboratory of Pharmacy Faculty, Airlangga University, Surabaya.

\section{RESULTS}

A total of 28 mice were divided into seven groups with the following details:

1. Negative control: Normal mice with induction of soy extract

2. Pre-test: T2D mice

3. Placebo control: T2D mice with solvent induction (CMC Na)

4. Positive control: T2D mice with metformin

5. Test 1: T2D mice with Wilis variety of soybean extract induction

6. Test 2: T2D mice with Gema variety of soybean extract induction

7. Test 3: T2D mice with Argomulyo variety of soybean extract induction.

After the treatment and observation of the animal, try in accordance with the design made then obtained the data in Fig 1.

The average of blood glucose in mice before the diabetic model was $127.1 \pm 29 \mathrm{mg} / \mathrm{dl}$, after being conditioned into diabetic model had blood glucose level of $235.1 \pm 113 \mathrm{mg} / \mathrm{dl}$. It shows the animal model making the process of the diabetic model is said to be successful, more visible with Fig. 1.

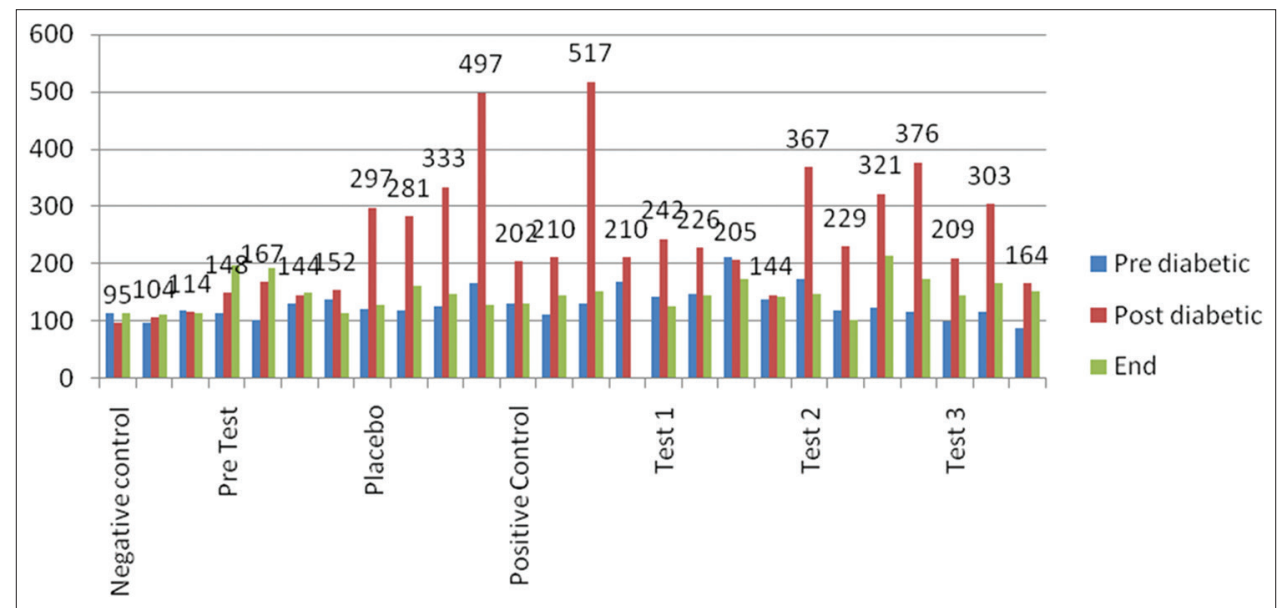

Fig. 1: Glucose in blood (mg/dl) levels in Type 2 diabetes animal models 
The extract of several varieties of soybean (G. $\max$ [L.] Merr.) was given to AGEs in mice as T2D animal models.

Table 1 shows that the T2D group (pretest) has the highest AGEs level, where there are many intermediate processes of dicarbonyl gum using a reactive carbonyl group attached to amino acids. The application of soy extract in T2D mice decreased AGEs product even though the AGEs were above the mice group with metformin.

Table 1: AGEs level $(\mu \mathrm{g} / \mathrm{ml})$ for each treatment group

\begin{tabular}{lll}
\hline Groups & AGEs $(\boldsymbol{\mu g} / \mathrm{ml})$ & ANOVA test P value \\
\hline Negative control & $1.4000+6245$ & 0.066 \\
Pre-test & $3.600+3.0078$ & \\
Placebo & $1.725+0.5188$ & \\
Positive control & $0.575+0.0500$ & \\
T2D+Wilis extract & $1.025+0.6131$ & \\
T2D+Gema extract & $1.000+0.4243$ & \\
T2D+Argomulyo extract & $1.033+0.6658$ & \\
\hline AGEs: Advanced glycation end products
\end{tabular}

ANOVA test results on AGEs in mice of all groups did not have significant differences $(P=0.06)$.

Table 2 shows HbA1c in the T2D group with the induction of Gema and Argomulyo varieties of soybean extract having values below the normal mice group.

Table 2: The HbA1c (mmol/mol) levels in each group of mice

\begin{tabular}{lll}
\hline Groups & HbA1c $(\mathbf{m m o l} / \mathbf{m o l})$ & ANOVA test P value \\
\hline Negative control & $27.33+1.155$ & 0.003 \\
Pre-test & $54.00+20.461$ & \\
Placebo & $34.25+5.439$ & \\
Positive control & $25.25+4.573$ & \\
T2D+Wilis extract & $28.50+5.066$ & \\
T2D+gema extract & $26.50+5.323$ & \\
T2D+Argomulyo extract & $24.00+2.646$ & \\
\hline
\end{tabular}

HbA1c: Hemoglobin A1c, T2D: Type 2 diabetes

ANOVA test results for HbA1c levels in blood showed no significant difference $(P=0.003)$. The result of LSD test between the groups was found that the group of T2D mice (pre-test) which had significantly different HbA1c levels with the soybean and metformin group but did not have a significant difference with the control placebo group (T2D+CMC solvent).

\section{DISCUSSION}

The initial stage of the Maillard reaction, also known as glycation, is glucose reacts with protein amino groups $\left(\mathrm{NH}_{2}\right)$ form a Schiff base. This reaction occurs quickly and reversibly, depending on the substrate concentration. Schiff base then converts into ketamine called a more stable amorous product (e.g. HbA1c). Free reactive carbonyl groups from this amadori product are responsible for some of the biological consequences of glycation. Products Amadori can be degraded to various carbonyl compounds more highly reactive such as 3-deoxyglucosone to react again with the amino groups are free to form intermediate products glycation which the intermediate products of these contribute to the formation of AGEs include dicarbonyl intermediates such as 3-deoxyglucosone, glyoxal, and methylglyoxal (formed by glucose auto-oxidation and glycolipid products). Early glycation products and intermediate undergo a complex series of chemical rearrangements further, to produce a compound of AGEs stable and irreversible, with a tendency to trigger ROS and interact with specific cell surface structures.

The fraction of total AGEs with relevant effects not only for the structure and function of proteins but also as mediators of biological responses has been characterized in tissues. These compounds include as follows:
1. Imidazoline formed by the 3-deoxyglucosone reaction and the arginine residue in the protein

2. $\mathrm{N}$ - $\varepsilon$-carboxyethyl-lysine, a CML analog that is formed by the reaction of methylglyoxal with lysine

3. Glyoxal-lysine dimer

4. Methyl-glyoxal-lysine dimer, an imidazolium cross-link formed by glyoxal or methylglyoxal reactions with lysine residues in proteins [23].

AGEs make cellular damage through pathways of AGEs receptors and through intracellular reactive oxygen species (ROS) as well as the reciprocal AGEs process with ROS that will produce either one. ROS activates signaling pathways in the form of mitogen-activated protein kinase, protein kinase $\mathrm{C}$, Janus kinase/signal transducer, and activator of transcription, which has effects on proinflammatory and profibrotic cytokines [7]. AGEs were highest in the T2D group (pre-test), where many intermediate dicarbonyl glycation processes occurred using reactive carbonyl groups bonded with amino acids. The application of soy extract in T2D mice decreased AGEs product even though the AGEs were above the mice group with metformin.

Soy protein and isoflavonoids in soybeans improve insulin resistance and enhancement of insulin release [22]. This compound preserved islet mass by increasing $\beta$-cell count, proliferation, and survival in the pancreas. Fu demonstrated that genistein could prevent T2D through a direct protective action on $\beta$-cells without alteration of periphery insulin sensitivity [23]. Moreover, its antidiabetic mechanism involves activation of protein kinase A and extracellular signal-regulated kinases 1/2. However, Leiherer stated that genistein could activate AMPK and, in turn, led to a reduction in insulin sensitivity [24]. In a clinical trial, genistein and/or soybean extract reduced the risk of T2D in overweight women [25].

Glyceollins, the phytoalexins produced by soybeans in response to fungi, were demonstrated to reduce hyperglycemia. These compounds could improve glucose-stimulated insulin secretion and prevent apoptosis and dysfunction in $\beta$-cells in the presence of palmitate [25]. Accordingly, glyceollins enhanced glucagon-like peptide-1 (GLP-1) secretion in NCI-H716 cells, an intestinal enteroendocrine L cell line [26]. Soybean and/or its active components can treat T2D through multiple pathways mainly involving insulin resistance, $\beta$-cell function, and GLP-1 production.

The presence of phenolic, flavonoid, and isoflavone acids (phytochemical polyphenols and phytoestrogens) in soybean extracts has an insulin mimetic effect and acts as an $\alpha$-glycosidase inhibitor, slowing the absorption of polysaccharides, dextrin, and disaccharide in the intestinal so as to prevent glucose uptake [27]. If increased glucose can be prevented, then the impact of decreased in the formation of HbA1c and AGEs.

\section{CONCLUSIONS}

The soybean extract (G. $\max$ [L.] Merr.) effect on the lowest rate of AGEs in mice as T2D animal models is Gema variety, although there is no statistically significant difference with other varieties. The soybean extract (G. max [L.] Merr.) effect on the lowest rate of HbA1c in mice as T2D model animals is Argomulyo varieties although there is no statistically significant difference with other varietal groups

\section{ACKNOWLEDGMENT}

This work was funded by Research and Community Service Program for Research Group. The authors are grateful for Surabaya Health Polytechnics.

\section{AUTHOR'S CONTRIBUTIONS}

Juliana Christyaningsih has provided the design, intellectual content, innovations, and protocol for conducting the experiment along with mentorship, and sincerely authored the article. Taufiqurrahman has majorly 
performed the experiment in the laboratory. Sudjono has a minor role in conducting the experiment in the laboratory, and analysis of obtained data.

\section{CONFLICTS OF INTEREST}

The authors declare that there are no conflicts of interest regarding the publication of this article.

\section{REFERENCES}

1. Nayak S, Rao K, Patil N, Jayaprakash B, Priya DA, Balaji O, et al. Prevalence of diabetic retinopathy in type 2 diabetes mellitus: An observational study in Southern India. Asian J Pharm Clin Res 2017;10:201-3.

2. Halliwell B, Gutteridge JM. Free radical in biology and medicine. $3^{\text {rd }}$ ed. New York: Oxford University Press; 1999. p. 639-45.

3. Rahbani-Nobar ME, Rahimi-Pour A, Rahbani-Nobar M, Adi-Beig F, Mirhashemi SM. Total antioxidant capacity, superoxide dismutase and glutathione peroxidase in diabetic patients. Med J Islamic Acad Sci 1999; $12: 109-14$

4. Dröge W. Free radicals in the physiological control of cell function. Physiol Rev 2002;82:47-95.

5. Ueno Y, Kizaki M, Nakagiri R, Kamiya T, Sumi H, Osawa T, et al. Dietary glutathione protects rats from diabetic nephropathy and neuropathy. J Nutr 2002;132:897-900.

6. Sruthi TD, Satyavati K, Upendar C, Pradeep K. Antidiabetic activity and anti-oxidant activity of niddwin, a polyherbal formulation in alloxan induced diabetic rats. Int J Pharm Pharm Sci 2014;6:273-7.

7. Uribarri J, Tuttle KR. Advanced glycation end products and nephrotoxicity of high-protein diets. Clin J Am Soc Nephrol 2006;1:1293-9.

8. Baynes JW, Thorpe SR. Role of oxidative stress in diabetic complications: A new perspective on an old paradigm. Diabetes 1999;48:1-9.

9. Anderson MM, Requena JR, Crowley JR, Thorpe SR, Heinecke JW. The myeloperoxidase system of human phagocytes generates nepsilon(carboxymethyl)lysine on proteins: A mechanism for producing advanced glycation end products at sites of inflammation. J Clin Invest 1999; 104:103-13.

10. Oldfield MD, Bach LA, Forbes JM, Nikolic-Paterson D, McRobert A, Thallas $\mathrm{V}$, et al. Advanced glycation end products cause epithelialmyofibroblast transdifferentiation via the receptor for advanced glycation end products (RAGE). J Clin Invest 2001;108:1853-63.

11. Hatfield J, Mulfinger L. Advanced glycation end-products (AGEs) in hyperglycemic patients. J Young Invest 2005; 13:575

12. Huebschmann AG, Regensteiner JG, Vlassara H, Reusch JE. Diabetes and advanced glycoxidation end products. Diabetes Care 2006;29:1420- 32
13. Prakash D, Suri S, Upadhyay G, Singh BN. Total phenol, antioxidant and free radical scavenging activities of some medicinal plants. Int $\mathrm{J}$ Food Sci Nutr 2007;58:18-28.

14. Dajanta K, Janpum P, Leksing W. Antioxidant capacities, total phenolics and flavonoids in black and yellow soybeans fermented by Bacillus subtilis: A comparative study of Thai fermented soybeans (thuanao). Int Food Res J 2013;20:3125-32.

15. Christyaningsih J, Yulia R. The effects glycine max L. Merr on lipid peroxidation and kidney's histopathology in lead intoxication mice. Res J Pharm Biol Chem Sci 2015;6:1204-10.

16. Yulia R, Pradana AT, Sie SS, Suri FA, Formulation and physical characteristics of Detam II soybean (Glycine max (L.)Merr) tablet with various concentration of silicon dioxide and magnesium stearate. Asian J Pharm Clin Res 2018;11:283-8.

17. Yulia R, Christyaningsih J, Irmasari V. The antioxidant substances profile of glycine max 1. Merr. Var. Detam II ultrasonic extract. Res J Pharm Biol Chem Sci 2015;6:502.

18. Accorsi-Neto A, Haidar M, Simões R, Simões M, Soares J Jr. Baracat E, et al. Effects of isoflavones on the skin of postmenopausal women: A pilot study. Clinics (Sao Paulo) 2009;64:505-10.

19. Ma DF, Qin LQ, Wang PY, Katoh R. Soy isoflavone intake inhibits bone resorption and stimulates bone formation in menopausal women: Meta-analysis of randomized controlled trials. Eur J Clin Nutr 2008;62:155- 61

20. King AJ. The use of animal models in diabetes research. Br J Pharmacol 2012;166:877-94.

21. Alam SA, Reddy SK, Baig AB, Reddy MK, Mohiuddin MO, Reddy MV, et al. Evaluation of antidiabetic and anti-lipidimic potential of kalongi sugar powder water extract in stz induced diabetic rats. Int J Pharm Pharm Sci 2013;5:94-6.

22. Behloul N, Wu G. Genistein: A promising therapeutic agent for obesity and diabetes treatment. Eur J Pharmacol 2013;698:31-8.

23. Fu Z, Gilbert ER, Pfeiffer L, Zhang Y, Fu Y, Liu D, et al. Genistein ameliorates hyperglycemia in a mouse model of nongenetic type 2 diabetes. Appl Physiol Nutr Metab 2012;37:480-8.

24. Leiherer A, Mündlein A, Drexel H. Phytochemicals and their impact on adipose tissue inflammation and diabetes. Vascul Pharmacol 2013;58:3- 20 .

25. Chang CL, Lin Y, Bartolome AP, Chen YC, Chiu SC, Yang WC, et al. Herbal therapies for type 2 diabetes mellitus: Chemistry, biology, and potential application of selected plants and compounds. Evid Based Complement Alternat Med 2013;2013:378657.

26. Park S, Ahn IS, Kim JH, Lee MR, Kim JS, Kim HJ, et al. Glyceollins, one of the phytoalexins derived from soybeans under fungal stress, enhance insulin sensitivity and exert insulinotropic actions. J Agric Food Chem 2010;58:1551-7.

27. Patel DK, Prasad SK, Kumar R, Hemalatha S. An overview on antidiabetic medicinal plants having insulin mimetic property. Asian Pac J Trop Biomed 2012;2:320-30. 